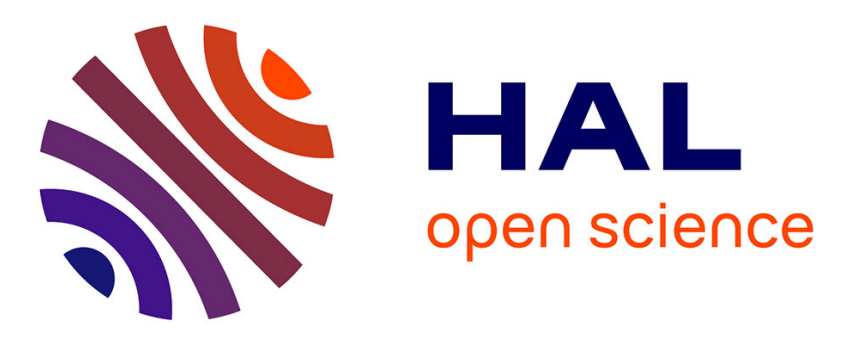

\title{
Are Item Attributes a Good Alternative to Context Elicitation in Recommender Systems?
}

\author{
Amaury L'Huillier, Sylvain Castagnos, Anne Boyer
}

\section{To cite this version:}

Amaury L'Huillier, Sylvain Castagnos, Anne Boyer. Are Item Attributes a Good Alternative to Context Elicitation in Recommender Systems?. 25th Conference on User Modeling, Adaptation and Personalization (UMAP 2017), Jul 2017, Bratislava, Slovakia. hal-02471982

\section{HAL Id: hal-02471982 https://hal.science/hal-02471982}

Submitted on 9 Feb 2020

HAL is a multi-disciplinary open access archive for the deposit and dissemination of scientific research documents, whether they are published or not. The documents may come from teaching and research institutions in France or abroad, or from public or private research centers.
L'archive ouverte pluridisciplinaire HAL, est destinée au dépôt et à la diffusion de documents scientifiques de niveau recherche, publiés ou non, émanant des établissements d'enseignement et de recherche français ou étrangers, des laboratoires publics ou privés. 


\section{Are Item Attributes a Good Alternative to Context Elicitation in Recommender Systems?}

\author{
Amaury L'Huillier \\ LORIA - University of Lorraine \\ Campus Scientifique, B.P. 239 \\ Vandoeuvre, France 54506 \\ amaury.lhuillier@loria.fr
}

\author{
Sylvain Castagnos \\ LORIA - University of Lorraine \\ Campus Scientifique, B.P. 239 \\ Vandoeuvre, France 54506 \\ sylvain.castagnos@loria.fr
}

\author{
Anne Boyer \\ LORIA - University of Lorraine \\ Campus Scientifique, B.P. 239 \\ Vandoeuvre, France 54506 \\ anne.boyer@loria.fr
}

\begin{abstract}
Context-aware recommendation became a major topic of interest within the recommender systems community as the context is crucial to provide the right items at the right moment. Many studies aim at developing complex models to include contextual factors in the recommendation process. Despite a real improvement on the recommendations quality, such contextual factors face users' privacy and data collection issues. We support the idea that context could be expressed in term of item attributes rather than contextual factors. To investigate that hypothesis, we designed an online experiment where 174 users were asked to describe the context in which they would listen the proposed songs for which we collected 12 musical attributes. We make available all the material collected during this study for research purposes and non-commercial use.
\end{abstract}

\section{KEYWORDS}

Context-Aware Recommender System; Context Elicitation; User Study

\section{INTRODUCTION}

Since it has been demonstrated that recommendations quality is not only about precision relatively to users preferences, current recommendation algorithms aim at integrating human factors in the recommendation process. Among them, context which is used to provide the right recommendations at the right moment is one of the most studied factors and its benefits no longer have to be demonstrated [1]. For example, context is crucial to recommende the right genre of music to a user in harmony with his activity or mood, or to recommend exhibits in a museum according to user's timeframe and people accompanying him.

Traditional Context-Aware Recommender Systems (CARS) collect and exploit information about the user situation (individuality, activity, location, time, and relations). Such information can be collected in several ways, by using sensors of the devices (GPS, temperature, light,...) or by cross-checking information gathered from other sources (e.g. inferring the weather from the geolocalization) [1]. A system can also directly question users about their

Permission to make digital or hard copies of part or all of this work for personal or classroom use is granted without fee provided that copies are not made or distributed for profit or commercial advantage and that copies bear this notice and the full citation on the first page. Copyrights for third-party components of this work must be honored. For all other uses, contact the owner/author(s).

UMAP '17, July 09-12, 2017, Bratislava, Slovakia

(C) 2017 Copyright held by the owner/author(s). 978-1-4503-4635-1/17/07.

DOI: http://dx.doi.org/10.1145/3079628.3079651 context ${ }^{1}$. Once contextual factors are defined, several methods are used to exploit them as matrix factorization [2], tensors [5] or graph-based approaches [7]. Despite unquestionable benefits in term of recommendation quality, such approaches face many issues. First, collecting such information is intrusive, some researches have demonstrated that collecting personal data becomes less and less desirable [4] and could lead to mistrust [6]. Second, context is known to be a very dynamic dimension and changes of one contextual factors can lead to a completely different context. Such models then require a non-stop tracking to detect any change of contextual dimension in order to adapt their recommendations and this point supports the previous discussed limitation. Third, required pieces of information are sometimes partially or non observable by the system due to technical or privacy preservation issues (as an example, users may have blocked the geolocalization on their smartphone making them obsolete).

For all these reasons, we proposed in 2015 a new definition of context based on the sol basis of consumed item attributes [3]. Our model was based on attributes diversity evolution over time and was used to isolate sequences of consultations sharing similar attributes called Implicit Context. Thus, context was no more defined by user situation description but according to item attributes values and their evolutions. Rather than finding items consumed in similar context to provide recommendations, our model could be used to extract the dimensions (attributes) that characterize the current implicit context. Adapting recommendations to these implicit context could be a new way to provide contextualized recommendations. However, no existing relations between the set of features discribing an item and explicit context characteristics were shown.

With the study proposed in this paper, we intend to provide a real dataset to investigate the potential links between context features and item attributes. More specififically, we wonder how users associate items with explicit contexts in an online music service. We used a musical dataset in our study as listening contexts are numerous, can easily be made explicit, and finding item attributes does not constitute an obstacle. Such study could also fit e-learning, museum or e-commerce scenarii.

\section{EXPERIMENT SETUP}

For the purpose of our experiment, we created an online survey ${ }^{2}$ to collect users' point of view as regards the context in which they would listen to tracks. These latter were selected on the basis of their preferred genres. Our goal was not to find the most suitable

\footnotetext{
${ }^{1}$ https://www.spotify.com/, https://play.google.com/music/

${ }^{2} \mathrm{http}: / /$ movit.tv/
} 
tracks for each user but to find a way to collect information on how users assign context dimensions to tracks.

\subsection{MATERIALS}

Users were recruited using mailing lists and the average duration to complete the study was about twenty five minutes. The track dataset used contains 360 tracks randomly selected from a Last.fm 3 dataset collected from 28 June 2005 to 18 December 2014. We choose to randomly select tracks in a large dataset (more that 170,000 tracks) to avoid bias due to popularity. 30 tracks were selected for each of the following genre: rock, pop, rap, country, punk, jazz, hip-hop, classical, folk, metal, electronic, blues. The only selection criteria were to have only one track per artist for all the selected tracks and to ensure that every attributes could be retrieved through the Spotify API ${ }^{4}$. We then gathered 12 attributes for each track (10 attributes tracks, and 2 for artists).

- TRACK ATtributes: acousticness, danceability, duration, energy, instrumentalness, liveness, loudness, speechiness, tempo, valence;

- ARTIST ATTRIBUTES: genre, popularity.

In the first part of the survey, users were asked to give some demographic information (age, gender, socio-professional category) and some information about their listening habits (preferred genre, favorite place to listen to music, listening time per day, how they chose their music). The second part of the survey consisted in presenting 15 tracks to each user according to their prefered genres and ask them to assign adapted contexts to these tracks (see Table $1)$.

Table 1: Context dimensions and conditions collected

\begin{tabular}{|l|l|}
\hline Context dimensions & Context conditions \\
\hline Activity & $\begin{array}{l}\text { relaxing, cleaning-up, cooking, driving, } \\
\text { partying, reading, exercising, thinking, } \\
\text { traveling, waking up, walking, working }\end{array}$ \\
\hline Day & morning, day, evening, night \\
\hline Energy & quiet, normal, energetic \\
\hline Environment & personal, professional \\
\hline Place & indoors, outdoors \\
\hline Season & spring, summer, fall, winter \\
\hline Social & alone, family, friends, couple \\
\hline Weather & sunny, rainy, snowy, cloudy \\
\hline Week & week, week-end \\
\hline
\end{tabular}

\subsection{RESULTS}

In order to reduce bias due to non conscientious responses, we decided to discard users who did not finished the study and obtained a final dataset of 172 users. By discarding records for tracks which were disliked (it is meaningless to ask users to specify the context for a track they will not listen to), we got a dataset of 1,507 tracks annotated (see Figure 1 for repartition).

\footnotetext{
${ }^{3} \mathrm{http}: / /$ www.last.fm/fr/api

${ }^{4}$ https://developer.spotify.com/web-api/
}

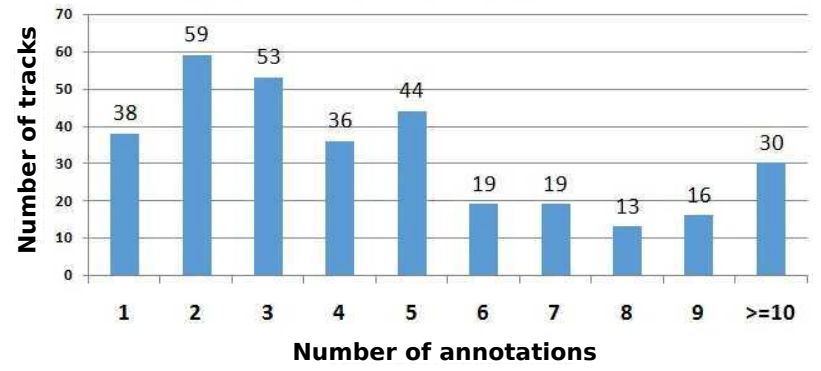

Figure 1: Number of times tracks were annotated

\section{CONCLUSION}

Implicit context appears to be a promising alternative to explicit context as it could be used to define user context while preserving his privacy and prevent data acquisition issues. In order to do so, overlaps between implicit and explicit context have to be highlighted and the data collected throught this study can be used to achieve this goal. We provide all the material collected during this study to encourage the research communtity to investigate relations between item attributes and explicit contexts.

\section{Link to the data: https://github.com/teamKiwi/umap2017}

This project has received funding from the European Union's Horizon 2020 research and innovation programme under grant agreement No 693150.

\section{REFERENCES}

[1] Gediminas Adomavicius and Alexander Tuzhilin. 2011. Context-aware Recommender Systems. Recommender Systems Handbook (2011), 217-253. https://doi.org/10.1007/978--0--387--85820--3_7

[2] Linas Baltrunas, Bernd Ludwig, and Francesco Ricci. 2011. Matrix Factorization Techniques for Context Aware Recommendation. In Proceedings of the Fifth ACM Conference on Recommender Systems (RecSys '11). ACM, New York, NY, USA, 301-304. https://doi.org/10.1145/2043932.2043988

[3] Sylvain Castagnos, Amaury L 'huillier, and Anne Boyer. 2015. Toward a Robust Diversity-Based Model to Detect Changes of Context. In 27th IEEE International Conference on Tools with Artificial Intelligence (ICTAI 2015). Vietri sul Mare, Italy. https://doi.org/10.1109/ICTAI.2015.84

[4] Lorrie Faith Cranor. 2005. Hey, That's Personal! In User Modeling 2005, Liliana Ardissono, Paul Bruna, and Antonija Mitrovic (Eds.). Lecture Notes in Computer Science, Vol. 3538. Springer Berlin Heidelberg, 4-4. https://doi.org/10.1007/11527886_2

[5] Balázs Hidasi and Domonkos Tikk. 2012. Fast ALS-Based Tensor Factorization for Context-Aware Recommendation from Implicit Feedback. Springer Berlin Heidelberg, Berlin, Heidelberg, 67-82. https://doi.org/10.1007/978-3-642-33486-3_5

[6] Bart P. Knijnenburg and Alfred Kobsa. 2013. Making Decisions About Privacy: Information Disclosure in Context-Aware Recommender Systems. ACM Trans. Interact. Intell. Syst. 3, 3, Article 20 (Oct. 2013), 23 pages. https://doi.org/10.1145/2499670

[7] Hao Wu, Kun Yue, Xiaoxin Liu, Yijian Pei, and Bo Li. 2015. Context-Aware Recommendation via Graph-Based Contextual Modeling and Postfiltering. International Journal of Distributed Sensor Networks 11, 8 (2015), 613612. 